\title{
Determination of co-site work conditions of selected wideband radio station by measurement method
}

\section{Rafal Polak}

Rafal Polak, "Determination of co-site work conditions of selected wideband radio station by measurement method," Proc. SPIE 11442, Radioelectronic Systems Conference 2019, 114421E (11 February 2020); doi: $10.1117 / 12.2565749$

SPIE. Event: Radioelectronic Systems Conference 2019, 2019, Jachranka, Poland 


\title{
Determination of co-site work conditions of selected wideband radio station by measurement method
}

\author{
Rafał Polak*a

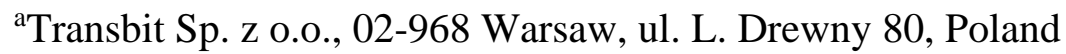 \\ *rafal.polak@transbit.com.pl; phone +48 534606 519; fax +48 2255048 10; transbit.com.pl
}

\begin{abstract}
The development of radio communications, in particular, appearance of radios (narrowband radios, broadband radios and radio relays) enabling the voice and data transmission services in digital modes has resulted in the use of radio communication devices at each, stationary and mobile command posts. One of the challenges faced by those who organize the radio communication systems is to ensure the internal compatibility of the radio system (suppressing internal interferences). The most difficult problem in that area is the frequency planning for radios located at the same object (co-site work). An incorrect assignment of frequencies for co-site radios may lead to degradation of communication or even may result in a lack of communication.

An advanced frequency planning and the knowledge on the impact of a strong interference signal on the required level of useful signal can have a critical meaning for the radio communication system, especially because of the limited number of frequency resources and requirements for minimizing of the radio link signal level ${ }^{[1]}$.

The modern electronic warfare includes an activity related to the electronic attack, oriented towards degradation or destruction of radio electronic devices by the use of electromagnetic energy and radio electronic security, oriented towards protection of radio electronic devices against the effects of use of electromagnetic energy.

An important activity of the radio electronic security is the immunizing radio electronic devices against signals which degrade, neutralize or completely block the ability of their work. Because of thus he activity oriented towards the fight against internal system interference is the foundation for preparing radio system against radio jamming.
\end{abstract}

Keywords: broadband radio station, co-site work, interferences, UHF

\section{INTRODUCTION}

The article presents performances of a broadband radio station operating in the UHF range $(225-400 \mathrm{MHz})$ and selected measure results of the co-site operation of a broadband radio in the presence of strong interference. The measure results were used to analyze the impact of a strong interference signal from a co-site radio on the useful communication range. For calculating the level of the interfering signal and the admissible level of the interfering signal the Longley Rice radio frequency attenuation model was used ${ }^{[2]}$.

\section{LONGLEY-RICE PATH ATTENUATION MODEL}

Path attenuation is dependent on many variables and has been a subject of long-term research that has led to the development of numerous models of radio path attenuation, varying in complexity and scope of application ${ }^{[3]}$. Some examples of models can be seen in Table 1 . The basic requirement for the radiocommunication planning system is to determine with high accuracy the value of useful and interfering signal levels at the signal reception site. For this purpose, it is necessary to know reliable radio path attenuation models taking into account a number of parameters.

Radioelectronic Systems Conference 2019, edited by Piotr Kaniewski, Jan Matuszewski, Proc. of SPIE Vol. 11442, 114421E · C 2020 SPIE · CCC code: 0277-786X/20/\$21 · doi: 10.1117/12.2565749 
Table 1. Parameters of various radio path attenuation models.

\begin{tabular}{|c|c|c|c|c|}
\hline Author & $\begin{array}{l}\text { Frequency } \\
\qquad(\mathrm{MHz})\end{array}$ & $\begin{array}{c}\text { Distance } \\
(\mathbf{k m})\end{array}$ & $\begin{array}{c}\text { HT (m) } \\
\text { Height of } \\
\text { Transmitter } \\
\text { antenna }\end{array}$ & $\begin{array}{l}\text { HR (m) } \\
\text { Height of } \\
\text { Receiver } \\
\text { antenna }\end{array}$ \\
\hline Y. Okumura & $15-1920$ & $1-100$ & $30-1000$ & \\
\hline M. Hata & $150-1500$ & $\geq 1$ & $30-200$ & $1-10$ \\
\hline COST 231 & $800-2000$ & $0.02-5$ & $4-50$ & $1-3$ \\
\hline H. Xia & 900,1900 & $0.001-2$ & $3.2,8.7,13.4$ & 1.6 \\
\hline V. Erceg & 1956 & $0.01-0.5$ & $3.3,6.6$ & 1.5 \\
\hline D. Har & 900,1900 & $0.06-2$ & $3.2,8.7,13.4$ & 1.6 \\
\hline A. Kanatas & 1890 & $0.02-0.18$ & 4 & 1.7 \\
\hline H. Masui & $\begin{array}{c}3350,8450,15 \\
750\end{array}$ & $0.02-0.5$ & 4 & 2.7 \\
\hline Y. Oda & $457-15450$ & & $\geq 20$ & \\
\hline T. Rao & $200,400,450$ & $0.5-10.5$ & $\geq 20$ & 3 \\
\hline N. Blaunstein & $902-928$ & & 7 & $2-3$ \\
\hline W. Young & $\begin{array}{c}150,450,800,3 \\
700\end{array}$ & $0.108-16.3$ & 138 & 2 \\
\hline
\end{tabular}

Different models determine the attenuation parameter for different frequency bands and geometry of the radio paths with different precision. The simplest models of RF path attenuation include a minimum set of parameters, e.g. distance and frequency, which is why they are not accurate. More precise models require additional consideration of relatively numerous constant and variable parameters that result from the type of the substrate, its topography and coverage, the state of the atmosphere (including humidity, pressure and temperature) and the height of the antennas suspension.

Using the L-R model to determine path attenuation allows to include terrain profiles. This model works correctly for the following parameters:

- $\quad$ ranges from 1 to $2000 \mathrm{~km}$;

- $\quad$ antennas suspended at heights $(0.5 \div 3000) \mathrm{m}$ above the ground;

- frequencies in the $20 \mathrm{MHz} \div 40 \mathrm{GHz}$ range covering most military wireless systems.

The L-R model requires the following input data:

- $\quad f[\mathrm{MHz}]$ - carrier frequency;

- $\quad d[\mathrm{~km}]$ - the distance between the transmitting antenna and the receiving antenna calculated along the curvature of the so-called big wheel;

- $\quad d_{L}[\mathrm{~km}]$ - the horizon distance;

- $\quad h_{g 1}, h_{g 2}[\mathrm{~m}]$ - height of the antennas above the Earth's surface;

- $\quad N s$ - refractive index on the Earth's surface;

- $\quad$ effective Earth radius $a_{s}=6370 \cdot\left[1-0,04665 \cdot \exp \left(0,005577 N_{s}\right)\right]^{-1}$. It typically takes the value of $8497 \mathrm{~km}$ for $N_{s}$ $=301$;

- $\quad$ climatic parameters (pressure $\mathrm{p}$, temperature $\mathrm{T}$, humidity e); 
- relative permittivity or relative dielectric constant $\varepsilon$ - the value of this parameter can be taken equal to 22 for the land, 80 for the sea;

- conductivity $\sigma$ - the value of this parameter can be taken as 0.003 for the land and 5.0 for the sea.

It is also necessary to have knowledge about additional parameters characterizing the path, i.e.:

- $h_{e l}, h_{e 2}$ - effective height of antennas - values calculated depending on the location of the antennas;

- $\mathrm{d}_{\mathrm{L} 1}, d_{\mathrm{L} 2}$ - radio horizon distance for both antennas;

- $\theta_{e l}, \theta_{e l}$ - radio horizon elevation angles;

- $\theta$ - angular distance for an off-horizon path;

- a parameter characterizing the terrain folding $\Delta h(d)$.

To determine the path attenuation $\left(L_{c r}\right)$ the wave attenuation in free space $\left(L_{b f}\right)$ is calculated, which is increased by the reference attenuation $\left(A_{c r}\right)$ calculated on the basis of the actual or statistical field profile:

$$
L_{c r}=L_{b f}+A_{c r}[\mathrm{~dB}]
$$

The path attenuation in free space expressed in $\mathrm{dB}$ is given by the formula:

$$
L_{b f}=32,45+20 \log _{10} f+20 \log _{10} d[\mathrm{~dB}]
$$

The calculation $\mathrm{A}_{\mathrm{cr}}$ is definitely more complex. Three methods are used to correspond to various propagation phenomena, which have the greatest significance depending on the distance between the transmitter and receiver:

- within the visibility range of the antennas, optical patterns of two beams (direct and reflected from the Earth's surface) are used. Within the range of antenna visibility, attenuation relative to attenuation in free space is increased by:

$$
A_{c r}=-10 \log _{10}\left[1+R_{e}^{2}-2 R_{e} \cos \left(\frac{2 \pi \Delta r}{\lambda}-c\right)\right]+G_{p}-10 \log _{10}\left(g_{o 1} g_{o 2}\right)[\mathrm{dB}]
$$

Here $g_{o 1}$ and $g_{o 2}$ represent the directive gain for each antenna in the direction of the other, while $2 \pi \Delta r / \lambda$ is the path length difference between direct and ground-reflected rays, expressed in electrical radians and in degrees. $R_{e}$ is the magnitude of an effective reflection coefficient and $c$ is its phase relative to $\pi$ radians. Assuming matched polarizations, the median path antenna gain may be approximated as $G_{p}$

- close to the horizon the diffraction phenomenon dominates, where the attenuation results from the diffraction over terrain obstacles on both radio horizons and the terrain unevenness between them. The attenuation is calculated as a weighted average of two estimates: for relatively flat terrain and for highly irregular terrain. The reference attenuation is calculated from the formula:

$$
A_{d}=(1-w) A_{k}+w A_{r}[\mathrm{~dB}]
$$

Where:

experimentally determined coefficient $w$ is defined as:

$$
w=\left\{1+0,1\left[\frac{\Delta h(d)}{\lambda}\left(\sqrt{\frac{h_{e 1} h_{e 2}+C}{h_{g 1} h_{g 2}+C}}+\frac{a \theta_{e}+d_{L}}{d}\right)\right]^{\frac{1}{2}}\right\}^{-1}, \text { dla } \frac{\Delta h(d)}{\lambda} \leq 1000
$$

For low antennas with known path parameters $\mathrm{C}=10$. Otherwise $\mathrm{C}=0$.

- far beyond the horizon, forward scatter is usually of major importance.

In the considerations, we will mainly use the relation (3) to determine the level of the interfering signal and the required level of the useful signal. 


\section{RESULTS OF EXPERIMENTAL TESTS}

First, the measurement of the isolation between two spatially separated antennas of co-site work for four different distances $(3$ to $6 \mathrm{~m}$ ) was taken to check the actual damping between antennas. The measurements were performed in accordance with the research methodology from "Report ITU-R M.2244(11/2011) Isolation between antennas of IMT base stations in the land mobile service"[4]. The tests were carried out in an anechoic chamber. Figure 1 below illustrates the antenna isolation testing scheme

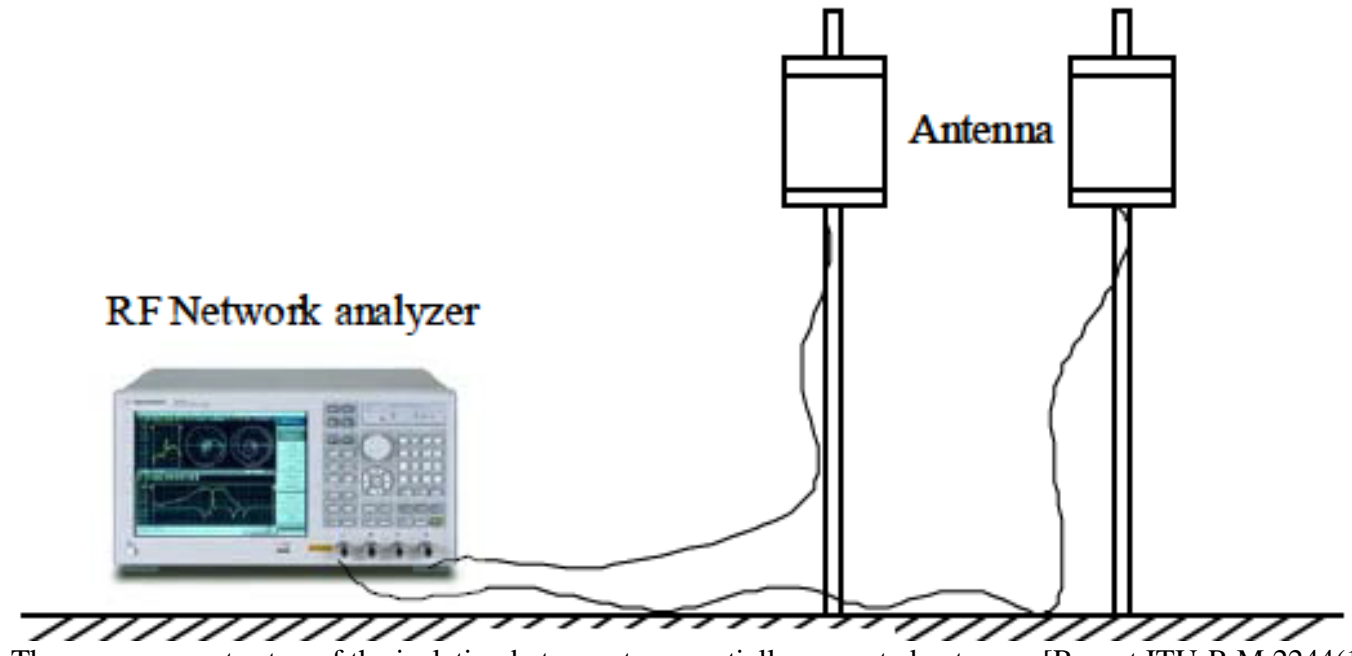

Figure 1. The measurement setup of the isolation between two, spatially separated antennas [Report ITU-R M.2244(11/2011)]

The measure results of antennas isolation in co-site conditions are presented in Figure 2 and average antenna isolation in co-site conditions in Table 2.

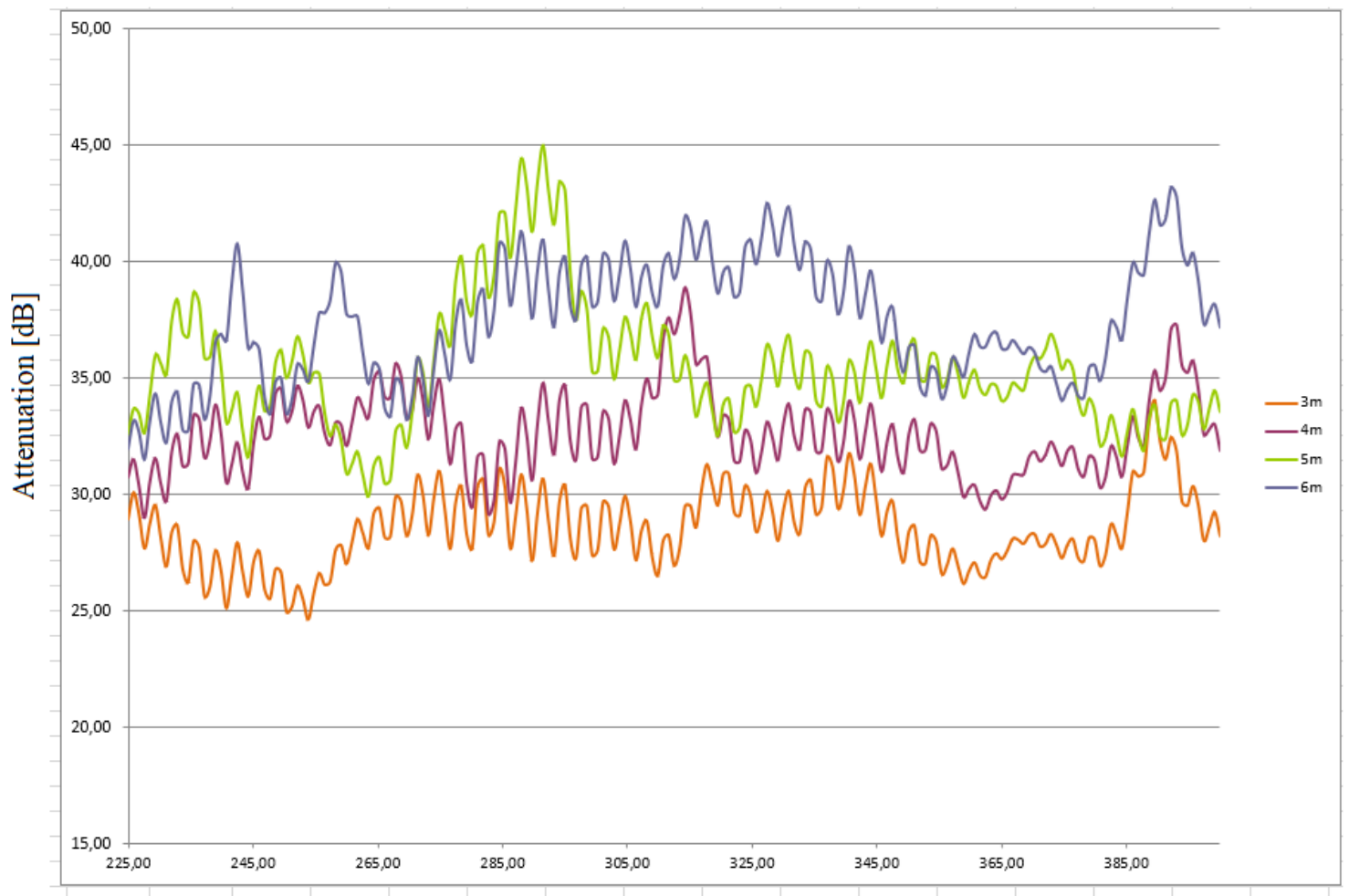

Frequency $[\mathrm{MHz}]$

Figure 2. The antennas isolation in co-site conditions 
Table 2. Averaged antennas insolation

\begin{tabular}{|c|c|}
\hline Distans [m] & Median [dB] \\
\hline 3 & 28,28 \\
\hline 4 & 32,48 \\
\hline 5 & 35,00 \\
\hline 6 & 37,56 \\
\hline
\end{tabular}

Having done the antenna isolation measurements, proper research was carried out, which the goal was to determine the minimum level of the useful signal (relation R1 - R3) in case of strong interference (radio station R2). The transmission was carried out using the following parameters BPSK modulations, $1 \mathrm{MHz}$ channel width, FEC 1/2 Błąd! Nie można odnaleźć źródła odwołania.. The measuring system is shown in the Figure 3:

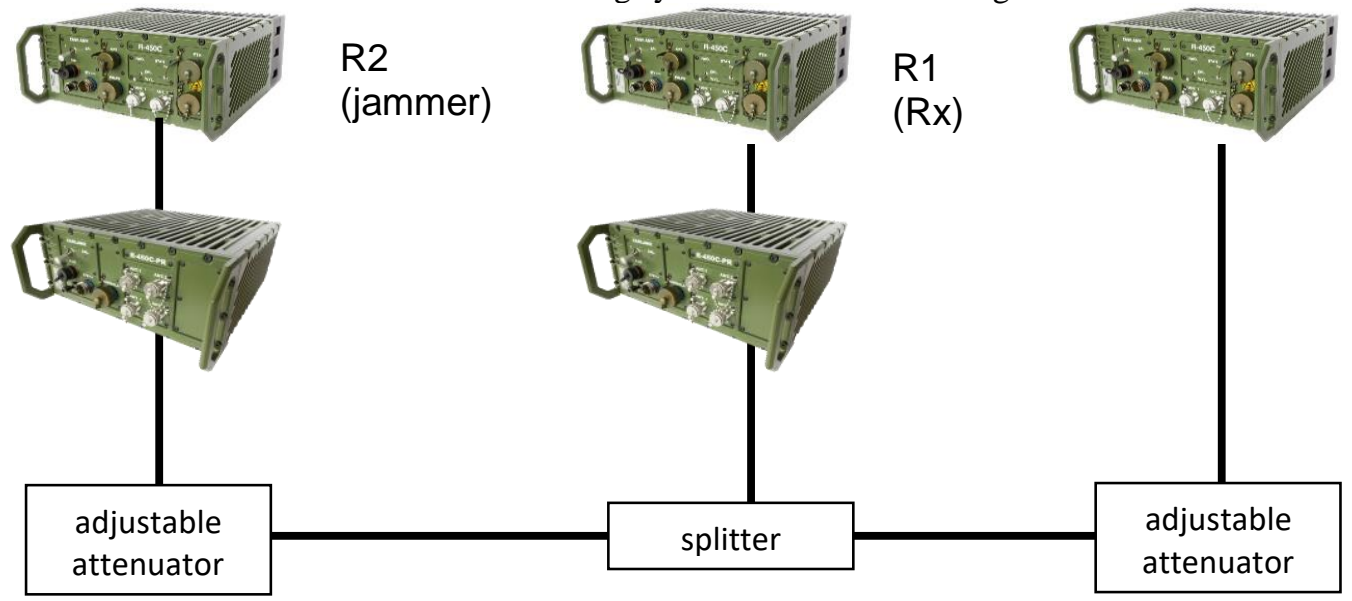

Figure 3. The measurement system scheme of the impact of co-site disturbances on wideband radios with preselectors The measurement system scheme is a simplified version of the actual measurement system because it does not represent its complexity. The actual measurement system is shown in the Figure 4.

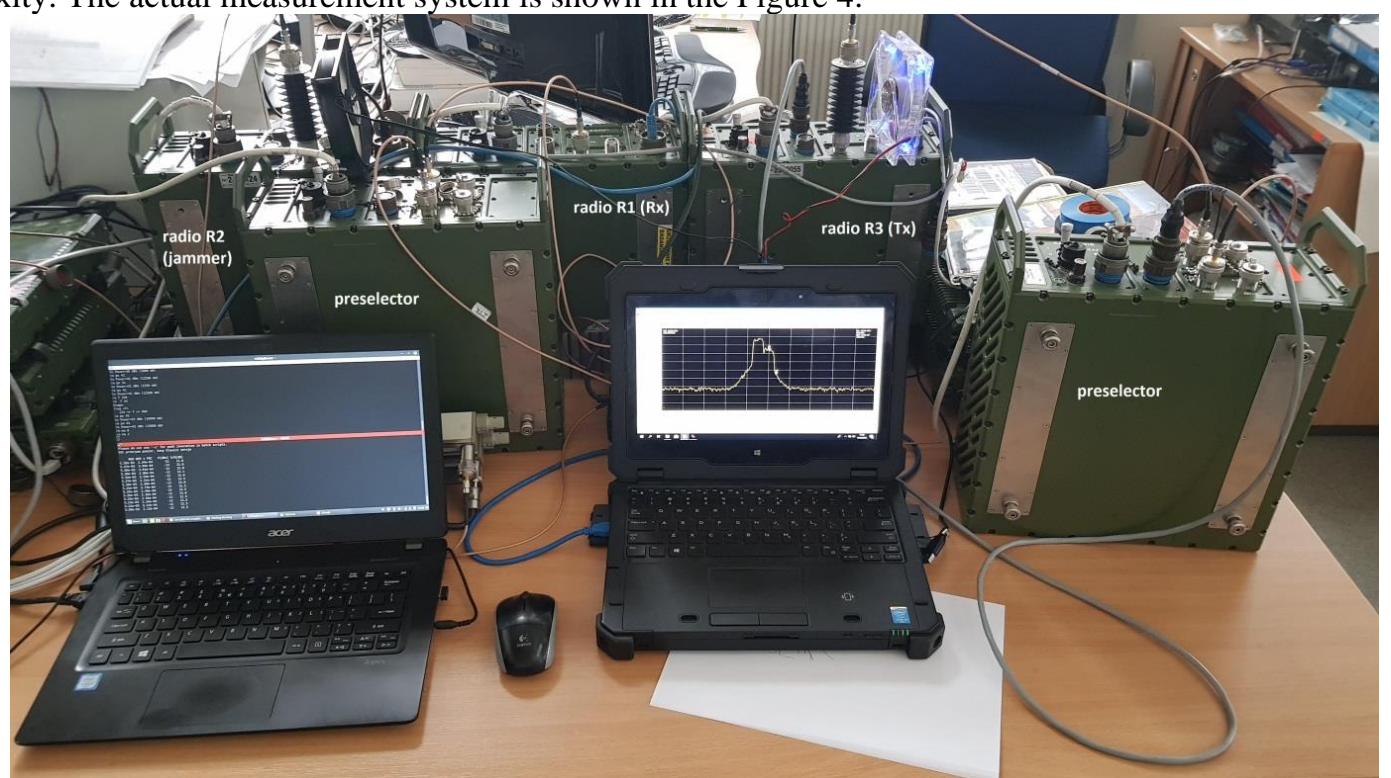

Figure 4. The actual measurement system of the impact of co-site disturbances on wideband radios with preselectors 
The level of the interfering signal at the antenna input of the receiving radio (R1) was $15 \mathrm{dBm}(43 \mathrm{dBm}-28 \mathrm{~dB})=15$ $\mathrm{dBm}$ (this corresponds to a distance between co-site antennas of 3 meters) for frequency of the R2 Radio frequency R1 $\mathrm{R} 3$ was shifted from radio frequency $\mathrm{R} 2$ every $1 \mathrm{MHz}$ after each measurement. The following measurement results were obtained (Table 3):

Table 3. Measurement results for a solution with two pre-selectors, a strong interference signal with a constant level and frequency of $300 \mathrm{MHz}$ at the input of the R1 receiver Measurement results for a strong constant interference signal and frequency of $300 \mathrm{MHz}$ at the input of the $\mathrm{R} 1$ receiver

\begin{tabular}{|c|c|c|}
\hline $\begin{array}{c}\text { Frequency } \\
\text { [MHz] }\end{array}$ & Input power on $\mathrm{R} 1$ [dBm] & RSSI on radio $\mathrm{R} 1$ [ dBm] \\
\hline 285 & -81 & -101 \\
\hline 286 & -79 & -98 \\
\hline 287 & -75 & -95 \\
\hline 288 & -62 & -82 \\
\hline 289 & -51 & -72 \\
\hline 290 & -49 & -64 \\
\hline 291 & -46 & -50 \\
\hline 292 & -44 & -40 \\
\hline 293 & -41 & -36 \\
\hline 294 & -39 & -35 \\
\hline 295 & -36 & -34 \\
\hline 296 & -33 & -33 \\
\hline 297 & -30 & -32 \\
\hline 298 & -27 & -31 \\
\hline 299 & -12 & -30 \\
\hline 301 & -12 & -31 \\
\hline 302 & -14 & -32 \\
\hline 303 & -30 & -32 \\
\hline 304 & -33 & -33 \\
\hline 305 & -35 & -35 \\
\hline 306 & -38 & -36 \\
\hline 307 & -42 & -39 \\
\hline 308 & -47 & -45 \\
\hline 309 & -49 & -53 \\
\hline 310 & -52 & -71 \\
\hline 311 & -61 & -79 \\
\hline 312 & -68 & -87 \\
\hline 313 & -77 & -96 \\
\hline 314 & -79 & -98 \\
\hline 315 & -81 & -100 \\
\hline
\end{tabular}

The graph below shows the RSSI signal strength level as a function of frequency (Figure 5): 


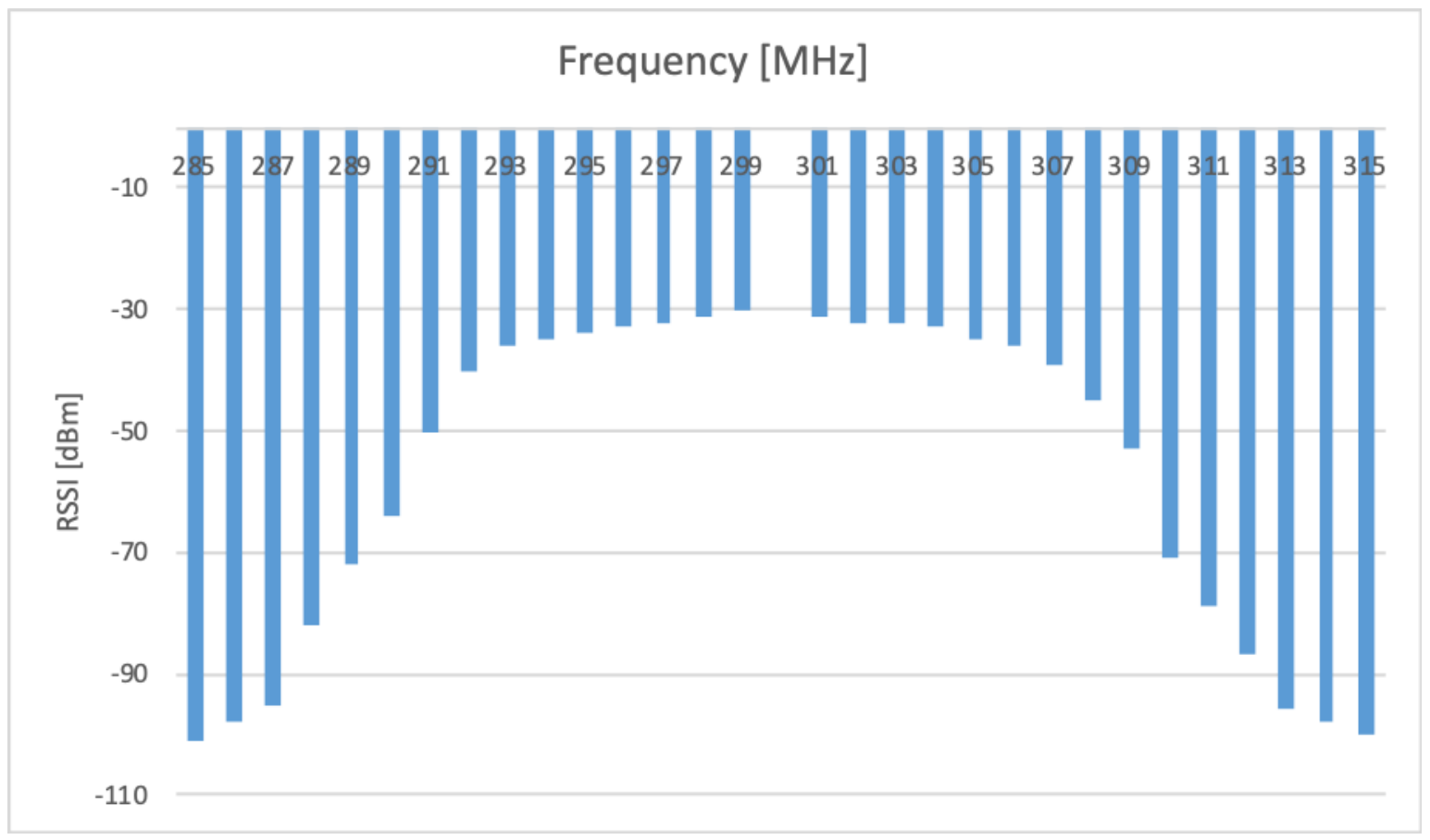

Figure 5. Graph of RSSI signal strength level as a function of frequency

In the case of a co-site relations, the use of preselectors allows the required separation in the frequency domain to be reduced to $15 \mathrm{MHz}$ to avoid interference from co-site radios (the distance between the antennas is 3 meters, and the interference radio operates with a maximum power of $20 \mathrm{~W}(43 \mathrm{dBm}))$. The usable signal level required is $-81 \mathrm{dBm}$.

Radio communication networks can work at different operating ranges (distances between correspondents in a radio network). If the network operates on a small area then there is no need to ensure operation at the sensitivity level of the radio. The simulation was performed using Matlab simulation software and Antenna Toolbox.

After the measurement of the co-site work, a simulation of attenuation path in free space was performed using the L-R radio attenuation model showing the possible maximum distances between the radio correspondents of a given radio network at a specified level of the interfering signal. With this software electromagnetic field strength maps for a transmitter operating at 20 Watt was shown. The Figure 6 shows the value of the electromagnetic field strength when operating at of $292 \mathrm{MHz}$ frequency. The distance between the transmitter and receiver is 450 meters. RSSI value is -40 $\mathrm{dBm}$. 


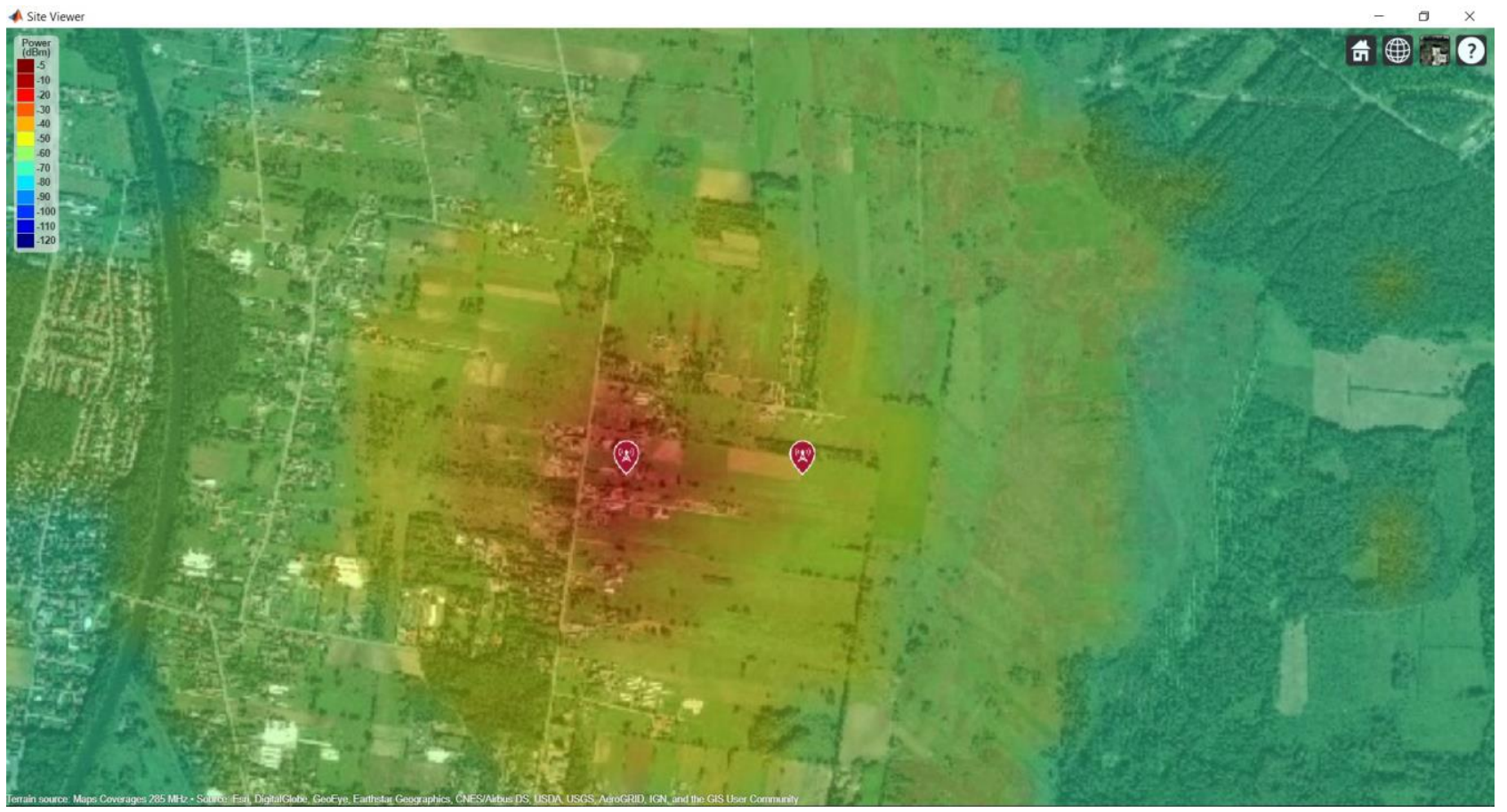

Figure 6. The electromagnetic field strength when operating at $292 \mathrm{MHz}$ frequency

The Figure 7 the operating frequency was $285 \mathrm{MHz}$, and the distance between the transmitter and receiver was 6550 meters. The RSSI value is approx. $-100 \mathrm{dBm}$.

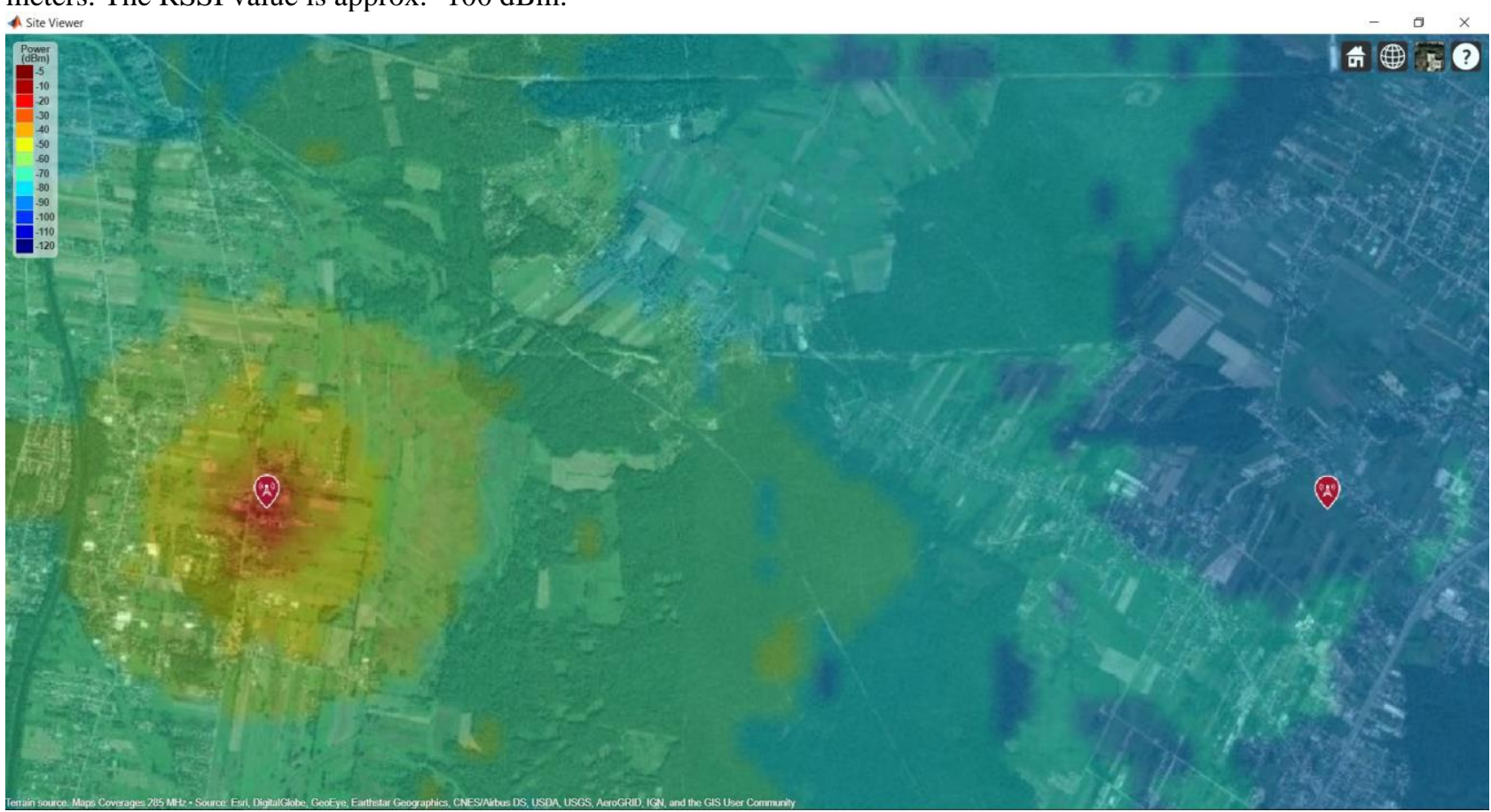

Figure 7. The electromagnetic field strength when operating at $285 \mathrm{MHz}$ frequency

Proc. of SPIE Vol. 11442 114421E-8 
The table below (Table 4) presents calculations by using the L-R radio attenuation model showing the possible maximum distances between radio correspondents of a given radio network at a given level of the interfering signal. The L-R model works correctly for ranges $1-2000 \mathrm{~km}$, so for ranges less than $1 \mathrm{~km}$, free-space path loss was used.

Table 4. Calculations by using the L-R radio attenuation model

\begin{tabular}{|c|c|c|c|c|}
\hline $\begin{array}{c}\text { Frequency in } \\
\text { relation } \\
\mathbf{R} 1-\mathbf{R 3}[\mathbf{M H z}]\end{array}$ & $\begin{array}{c}\mathbf{R 1} \text { power } \\
{[\mathbf{d B m}]}\end{array}$ & $\begin{array}{c}\mathbf{R S S I} \\
{[\mathbf{d B m}]}\end{array}$ & $\begin{array}{c}\text { Attenuation path } \\
{[\mathbf{d B}]}\end{array}$ & $\begin{array}{c}\text { Distance } \\
{[\mathbf{k m}]}\end{array}$ \\
\hline 285 & -81 & -101 & 124 & 6.55 \\
\hline 286 & -79 & -98 & 122 & 6.14 \\
\hline 287 & -75 & -95 & 118 & 4.41 \\
\hline 288 & -62 & -82 & 105 & 3.28 \\
\hline 289 & -51 & -72 & 94 & 0.59 \\
\hline 290 & -49 & -64 & 92 & 0.53 \\
\hline 291 & -46 & -50 & 89 & 0.47 \\
\hline 292 & -44 & -40 & 87 & 0.45 \\
\hline 293 & -41 & -36 & 84 & 0.35 \\
\hline 294 & -39 & -35 & 82 & 0.32 \\
\hline 295 & -36 & -34 & 79 & 0.29 \\
\hline 296 & -33 & -33 & 76 & 0.23 \\
\hline 297 & -30 & -32 & 73 & 0.18 \\
\hline 298 & -27 & -31 & 70 & 0.12 \\
\hline 299 & -12 & -30 & 55 & - \\
\hline
\end{tabular}

\section{SUMMARY}

The revealing deficits of spectral resources cause problems with the allocation of radio frequencies, especially on broadband radio stations ${ }^{[5]}$. This phenomenon is particularly important when co-site relation occurs. The article presents the results of an experimental research on antenna isolation allowing attenuation between antennas for co-site relation. Tests were carried out to measure the impact of the interference in co-operation on a broadband radio using preselectors. The article shows the results of insulation tests of antennas that allow dampening between antennas for co-site relations. The measurements presented show that it is sufficient to provide a separation of $15 \mathrm{MHz}$ to avoid interference from the co-site radio station. It is possible to provide less separation in the frequency range, for example, $12 \mathrm{MHz}$, but then the maximum radio station distance on the network must not be greater than $3.28 \mathrm{~km}$. The measurements received and calculated on the basis of their maximum operating distances on the radio network are very important for people planning radio communication and should be included in frequency allocation algorithms. This will allow for optimal allocation of spectral resources in the case of frequency set limitation.

\section{REFERENCES}

[1] Matyszkiel, R., Polak, R., Lubkowski, P., Laskowski, D.: „Mechanisms of immunization of broadband radio stations for targeted interference", XII Conference on Reconnaissance and Electronic Warfare Systems, Proceedings of SPIE, (2019).

[2] Longley A. G., Rice L. P.: „Prediction of Tropospheric Radio Transmission Loss Over Irregular Terrain”, ESSA (Environmental Science Services Administration) Technical Report ERL 79-ITS 67, (1968). 
[3] Suchański, M., Kaniewski, P., Matyszkiel, R., Gajewski, P. „Prediction of VHF and UHF wave attenuation in urban environment" MIKOM 19th International Conference on Microwaves, Radar \& Wireless Communications IEEE Conference Warsaw Poland, (2012).

[4] Report ITU-R M.2244(11/2011): „Isolation between antennas of IMT base stations in the land mobile service”, (2011).

[5] Matyszkiel, R., Kaniewski, P., Polak, R., Laskowski, D.: „The results of transmission tests of Polish broadband SRD radios", Communication and Information Technologies (KIT), (2017). 